\title{
USING REAL OPTIONS IN THE OPTIMAL DESIGN OF WATER DISTRIBUTION NETWORKS
}

\footnotetext{
João Marques ${ }^{1}$, Maria Cunha ${ }^{2}$ and Dragan Savic ${ }^{3}$

${ }^{1}$ Departamento de Engenharia Civil, Faculdade de Ciências e Tecnologia da Universidade de Coimbra, Portugal.

${ }^{2}$ Departamento de Engenharia Civil, Faculdade de Ciências e Tecnologia da Universidade de Coimbra, Portugal.

${ }^{3}$ Centre for Water Systems, School of Engineering, Computing and Mathematics, University of Exeter, United Kingdom.

${ }^{1}$ jmarques@dec.uc.pt, ${ }^{2} m c c u n h a @ d e c . u c . p t,{ }^{3}$ D.Savic@ex.ac.uk
}

\section{ABSTRACT}

Water supply systems have to satisfy water needs in terms of quantity and quality. The constant changes in urban areas require the regular adaptation of the water supply infrastructure to meet new realities. However, decisions to design and operate water networks have to be made under uncertainty. Flexibility is thus the key to more robust and confident decisions. An approach called Real Options (ROs) can be used here. This approach makes it possible to use adaptive strategies during the decision making process. Some decisions can be delayed until future conditions become known. Water distribution systems are very costly and complex infrastructures; once built, their operating structure cannot be changed significantly. This work presents an innovative ROs approach to define an objective function to cope with some future scenarios considered in a specific case study. The objective of the model proposed is to find a minimum cost solution for the first period of a planning horizon, while considering various possible future conditions that the network could have to cope with. The results of this work show that building flexibility into the decision strategy enables an adaptive approach to be taken that can avoid future lack of network capacity. In the case study, an adaptive design of the network incurs an extra initial cost, but this cost can easily be lower than the cost of reinforcing the network in a longer planning horizon. The real value of ROs is their ability to adapt systems to different future possible scenarios.

Keywords: water distribution networks, real options, simulated annealing, flexible design, uncertainty.

\section{INTRODUCTION}

Water distribution systems are costly and complex infrastructures which are meant to distribute water over a long planning horizon without interruption. Once built, networks cannot significantly change their operating conditions to adapt to new circumstances and the capacity and level of service cannot be increased easily. During the planning horizon, the pipe capacity declines as the roughness increases and the incidence of pipe burst also rises. Once 
laid, pipes cannot be reinforced without making large investments. Therefore, it is very important in water system planning to try to predict the future operating conditions. However, if the worst case scenario design is adopted the network could become overdesigned, with the result that resources are wasted and the water quality declines due to the lower velocity and higher water residence times. Moreover, cities are continually changing and the water supply systems have to be adapted for these changes. Sometimes a new urban or industrial area is built and the network has to be reinforced to accommodate the increased demand. But the opposite can also occur in areas whose population declines and the demand therefore falls. There are many sources of uncertainty in the future: technology, industry, economics, regulations and politics are some of them. It is very difficult to make correct forecasts under these uncertainties. Urban infrastructure planning is an immense and complex task. According to Haimes (1998) the great challenge for the scientific community of the third millennium will be to develop tools and technologies to support and maintain infrastructure. Several methods for effective planning in the area of water systems have appeared in the literature. To cope with future uncertainty, a flexible plan is required. In this context an approach called Real Options (ROs), originating in financial theory, could make an important contribution. Myers (1977) was the first to introduce the term Real Options (ROs), soon after the works of Black and Scholes (1973) and Merton (1973) which proposed a solution to the financial option valuing problem. Since then a large number of studies have been published where the concepts of ROs have been used in several fields. The ROs concept is analogous to financial options but ROs refer to physical assets such as buildings and infrastructure rather than financial instruments like stocks and shares.

Wang and Neufville (2004) divide ROs into two categories, ROs "on" systems and ROs "in" systems. ROs "on" systems focus on the external factors of a system and benefit from the use of financial valuation tools. On the other hand, ROs "in" systems incorporate flexibility into the structural design of a system and it is harder to value flexibility. This is the ROs category used to design water distribution networks.

The ROs approach facilitates adaptive strategies as it enables the value of flexibility to be included in the decision making process. Opportunities are provided for decision makers to modify and update investments when knowledge of future states is gained enabling them to identify the most appropriate long term intervention strategies. This gives a totally different perspective to a decision strategy, because there is no need for decisions to be inflexible and there is no specific date on which to take them.

A number of studies have developed ROs approaches to solve a variety of problems. Roberts and Weitzman (1981) analyse the nature of sequential investments during a time horizon. In industry $\mathrm{He}$ and Pindyck (1992) solve investment decisions with flexible production capacities. In petroleum exploration, Paddock et al. (1988) use ROs to evaluate the investment in an offshore platform. In electric power systems, Tannous (1996) compares flexible and 
rigid electrical systems. Other uses of ROs approaches include Nembhard and Akton (2010), who systemized applications of ROs to design and develop engineering problems and Neufville et al. (2006), reported the use of ROs in car parking problems. In the water industry, an ROs technique appears in the work of Woodward et al. (2011) to define maritime costal defences to reduce the risk of flooding. In the area of water systems expansion, Suttinon and Nasu (2010) present an ROs based approach where the demand increases. The work of Buurman, et al, ( 2009) and the work of Zhang and Babovic, (2011) apply ROs to the development of a maritime domain protection system. Zhang and Babovic (2012) also use an ROs approach to evaluate different water technologies into water supply systems under uncertainty. There is a vast body of literature reporting the use of ROs but, until now, it has only been possible to find the work of Huang et al. (2010) that describes the application of ROs to design of water distribution networks. The methodology used presents a flexible design tool based on decision scenario trees that reflect uncertainty associated with future demand for water. The authors use a genetic algorithm optimization model to find a flexible design to a simple case study.

This work presents an innovative and different approach where uncertainty is not only associated with future demand for water, but also, it considers new expansion scenarios for the network. These scenarios are organized through a decision tree. The investment and the corresponding design of the network have to cope with the first period, but they have to work well throughout the planning horizon. This work uses a minimum cost objective function and various scenarios are considered to predict different alternative future conditions. The objective function also includes a regret term used to approximate the cost of the ROs solution that must work well for all scenarios, with the cost of each scenario considered individually. Therefore, before running the model it is necessary to find the optimal solution for each scenario. The method proposed here to solve the optimization problem is a simulated annealing heuristic based on Aarts and Korst (1989). The work of Cunha and Sousa (1999) shows the capabilities of this method to find optimal solutions in water distribution network problems. This method was also used in aquifer management (Cunha, 1999); water treatment plants ((Afonso and Cunha, 2007); wastewater systems ((Zeferino, et al. 2012) and rail planning networks ((Costa, et al. 2013). The case study presented in section 3 explains how the ROs approach can be used and the benefits of using a flexible design.

The remainder of this study is organized as follows: in the next section a case study is presented to explain the method. A decision model is built and the results are shown. Then some comparisons are drawn with traditional approaches. Finally, the conclusions are systemized.

\section{CASE STUDY}


In this section, an ROs approach is used in a simple case study. This is a water distribution network inspired in (Taher \& Labadie, 1996). The layout of the network and characteristics of the pipes and nodes can be consulted in this work.

This is a simple new network with 10 nodes and 11 pipes supplied from a single reservoir with a free water surface elevation of $304.8 \mathrm{~m}$. The pump is used to increase pressure at the remote end nodes of the network. The efficiency of the pump is $80 \%$ and the daily consumption is 12 hours at demand condition (1) and the other 12 hours at demand condition (2). Demand condition (3) considers the instantaneous peak discharge and a fire flow in node 10. These demand conditions can be consulted in (Taher \& Labadie, 1996). The energy costs are $€ 0.18 / \mathrm{kWh}$ and should be evaluated for a 60 -year period by a discount rate of $4 \%$ year. This rate was fixed based on the work of $\mathrm{Wu}$ et al. (2010). The design of the network considers the 11 different commercial diameters presented in table 1 .

Table 1: Diameter, unit costs, Hazen-Williams coefficients

A network planning horizon of 60 years was taken for this case study, which was split into 4 periods. This subdivision considers periods of different lengths. It is supposed that in the first period $(T=1)$, no modifications will be needed and that conditions will remain the same for the first 20 years. In this first step of the decision-making process, 10 pipes and the head of the pumping station have to be designed for three different operating conditions. Periods $\mathrm{T}=2$ and $\mathrm{T}=3$, are short periods of 10 years each. The regional planning strategy assumes that the land use of some areas of the city is reviewed. Therefore, for $\mathrm{T}=2$ the authorities are planning to license a new industrial area (NIA) if enough companies show an interest and so the network will be expanded in this period. For $\mathrm{T}=3$, it is expected that a new residential area (NRA) might grow close to the industries, due to labour required for NIA, so the possible expansion of the network to the new residential area is considered. It is assumed that the pumps have to be changed every 20 years, so the pumps will have to be replaced in $\mathrm{T}=2$ and $\mathrm{T}=4$. In the last period, $\mathrm{T}=4$, the demand should be predicted. However the time horizon is large and it is very difficult to accurately predict how demand will vary during the last 20 years of planning. For the last period it is assumed that the demand might increase between 0 and $20 \%$, equally in all nodes in the network. The two different paths' scenarios that are possible in the last period are the $20 \%$ increase in demand and demand remaining constant. The potential expansion areas are shown by dashed pipe links in Fig. 1 and the characteristics of the new nodes and pipes are presented respectively in tables 2 and 3 .

Figure 1: Water distribution network inspired from Taher \& Labadie (1996) with possible expansion areas

Table 2: Characteristics of the new nodes 
To be cited as: Marques, J., Cunha, M., and D.A. Savić (2015), Using Real Options in the Optimal Design of Water Distribution Networks, Journal of Water Resources Planning and Management (ASCE), Vol. 141, No. 2, 04014052, doi: 10.1061/(ASCE)WR.1943-5452.0000448.

Table 3: Characteristics of the new pipes

As the planning horizon progresses and the pipes get older the wall roughness increases. The planning horizon for this case study is 60 years and the fall in pipe capacity should not be neglected for any future decision that has to be made. Based on the DWSD (2004) report, the Hazen-Williams coefficients of ductile iron pipes decreased at a fixed rate of 2.5 per decade. Of course this rate depends on many factors and is also time dependent. But to simplify matters, a fixed rate was assumed for the entire planning horizon. The demand will also vary. It was assumed that for the first 40 years' operation the demand would increase at a constant rate of $10 \%$ per decade. For the last period, the demand could stabilize or increase by no more than $20 \%$, as was supposed before. The main virtue of real options approach remains on the possibility to make midcourse corrections as new information comes. Thus, these assumptions can be adapted if required to new future realities.

Assuming a subdivided planning horizon, different conditions and possible expansions, a decision tree for all possible paths of the process and respective probabilities is shown in Fig. 2. This is a simple case study and the decision model can be easily solved. In real systems the complexity can increase and the computation effort too. One of the possibilities to obtain solutions in admissible time horizons is to use parallel computing.

Figure 2: Decision tree for the planning horizon

There are 8 different paths that can be tracked during the planning horizon of the network. In the first period $(\mathrm{T}=1)$ an initial design for the network is determined, in $\mathrm{T}=2$ the pumps have to be replaced and an NIA may or may not need to be supplied. An NRA might be built in $\mathrm{T}=3$. In the last period $\mathrm{T}=4$, the pumps have to be replaced and the demand for the last 20 years of the planning horizon is designated. Finally, the probabilities of the different scenarios are assigned to each path. These probabilities can be obtained by different methods, taking into account the urban planning and other plans for future developments and land use. Aggregating all the information, the probabilities can be given by experts. For this case study the probabilities considered for the different paths are shown in Fig. 2. In T=1, the probability of occurrence is 1 ; it is the only possibility. For $\mathrm{T}=2$, it is accepted that there is a $75 \%$ chance that an NIA will be built. The probability that an NIA is not built is the other $25 \%$. In $\mathrm{T}=3$ it will be decided if the NRA will be extended or not. If the NIA has been installed then it is more probable that the NRA will be built because of the labour needed for the industries, so the probability of constructing the NRA is higher in the upper paths of the decision tree. In the last period, $\mathrm{T}=4$, the demand has to be assigned. If the NIA or/and the NRA are built the probability of an increment in demand is higher. To conclude, the probability of the scenarios is calculated by multiplying the probabilities of all nodes on the path of that scenario, and they are shown in the last branches of the tree in Fig. 2. 
To be cited as: Marques, J., Cunha, M., and D.A. Savić (2015), Using Real Options in the Optimal Design of Water Distribution Networks, Journal of Water Resources Planning and Management (ASCE), Vol. 141, No. 2, 04014052, doi: 10.1061/(ASCE)WR.1943-5452.0000448.

203

204

205

206

207

208

209

210

211

\subsection{DECISION MODEL}

The decision model presented here is based on the ROs approach and aims to define an objective function to cope with all the different planning horizon paths that are considered in the case study. The objective function and the corresponding constraints of the model will determine a solution to implement in the first period, $\mathrm{T}=1$, but taking into account all the possible future conditions that the network could cope with. The proposed objective function $O F$ is given by Eq. 1 :

$$
O F=\operatorname{Min}(C i+C f+R)
$$

212 Where: $C i$ - cost of the initial solution to be implemented in year zero $(€)$; $C f$ - cost of the future conditions $(€)$ and $R$ - regret term $(€)$.

The objective function of Eq. 1 is written so that the solution for the first period, $\mathrm{T}=1$, can be determined taking into account the different paths of decisions that have to be made during the planning horizon. The objective function seeks to minimize not only the initial cost but also the probable future costs of the system. To take into account the differences between the costs of the general solution and the optimum costs for each scenario considered individually, a regret term is used in the objective function. The cost of the solution to implement is given by the sum of three terms. The term $C i$ computes the cost of the network for the first period $\mathrm{t}=1$ of planning and is given by Eq. 2 :

$$
C i=\left(\begin{array}{l}
\sum_{i=1}^{N P I}\left(\operatorname{Cpipe}_{i}\left(D_{i, 1}\right) L_{i}\right)+\sum_{j=1}^{N P U}\left(C p s_{j, 1}\right)+ \\
+\left(\sum_{d=1}^{N D C}\left(C e_{d} \cdot \sum_{j=1}^{N P U} \frac{\gamma \cdot Q P_{j, d, 1} \cdot H P_{j, d, 1}}{\eta_{j}} \cdot \Delta t_{d}\right) \cdot 365 \cdot \frac{(1+I R)^{N Y_{1}}-1}{I R \cdot(1+I R)^{N Y_{1}}}\right)
\end{array}\right)
$$

Where: NPI- number of pipes in the network; Cpipe $_{i}\left(D_{i, 1}\right)$ - unit cost of pipe $i$ as function of diameter $D_{i, 1}$ adopted $(€ / \mathrm{m}) ; D_{i, 1}$ - diameter of pipe $i$ installed in period $t=1(\mathrm{~mm}) ; L_{i}$ - length of pipe $i(\mathrm{~m})$; NPU - number of pumps in the network; $C p s_{j, 1}$ - pumping station costs of pump $j$ in the period $t=1(€)$; NDC - number of demand conditions considered for the design; $C e_{d}$ cost of energy in demand condition $d(€) ; \gamma$ - specific weight of water $\left(\mathrm{KN} / \mathrm{m}^{3}\right) ; Q P_{j, d, 1}$ discharge of pump $j$ in demand condition $d$ and for period $t=1\left(\mathrm{~m}^{3} / \mathrm{s}\right) ; H P_{j, d, 1}$ - head of the pump $j$ in the demand condition $d$ and for period $t=1(\mathrm{~m}) ; \eta_{j}$ - efficiency of pump $j ; \Delta t_{d}$ duration of demand condition $d(\mathrm{~h}) ; I R$ - annual interest rate for updating the costs and $N Y_{t}-$ number of years with the same conditions considered in the period $t=1$.

The initial cost is given by the sum of the cost of the pipes and the cost of the pumps and the energy cost. These costs are computed assuming $N Y_{1}=20$ which is the number of years of the first period. The other term of the objective function represents the future costs of all the 
To be cited as: Marques, J., Cunha, M., and D.A. Savić (2015), Using Real Options in the Optimal Design of Water Distribution Networks, Journal of Water Resources Planning and Management (ASCE), Vol. 141, No. 2, 04014052, doi: 10.1061/(ASCE)WR.1943-5452.0000448.

decision nodes designs (Eq. 3) weighted by the respective probability of each decision node that is presented in Fig. 2:

$$
C f=\sum_{\mathrm{s}=1}^{N S} \sum_{\mathrm{t}=2}^{N T I}\left(\text { Cfuture }_{t, s} \cdot \prod_{n t=2}^{t} \text { prob }_{n t, s}\right)
$$

Where: NS - number of scenarios; NTI - number of time intervals; Cfuturet,s - cost of the future path of designs in scenario s for period $t(€)$ and $\operatorname{prob}_{n t, s}$ - probability of the scenario $s$ in period $n t$

Adding up all possible future costs conditions, starting from $\mathrm{T}=2$, multiplied by the probability of occurrence of such costs, we get a weighted mean of the future costs for the

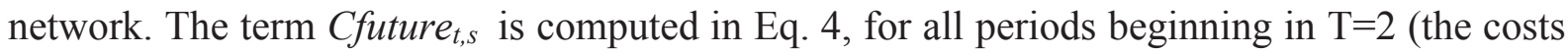
for the first period are already calculated in the Cinitial term) and it is given by the sum of three terms:

$$
\text { Cfuture }_{t, s}=\left(\begin{array}{l}
\sum_{i=1}^{N P I}\left(\operatorname{Cpipe~}_{i}\left(D_{i, t, s}\right) L_{i}\right) \cdot \frac{1}{(1+I R)^{Y_{t}}}+\sum_{j=1}^{N P U}\left(\operatorname{Cps}_{j, t, s}\right) \cdot \frac{1}{(1+I R)^{Y_{t}}}+ \\
+\left(\sum_{d=1}^{N D C}\left(C e_{d} \cdot \sum_{j=1}^{N P U} \frac{\gamma \cdot Q P_{j, d, t, s} \cdot H P_{j, d, t, s}}{\eta_{j}} \cdot \Delta t_{d}\right) \cdot 365 \cdot \frac{(1+I R)^{N Y_{t}}-1}{I R \cdot(1+I R)^{N Y_{t}}}\right) \cdot \frac{1}{(1+I R)^{Y_{t}}}
\end{array}\right)
$$

Where: Cpipe $_{i}\left(D_{i, t, s}\right)$ - unit cost of pipe $i$ as function of diameter $D_{i, t, s}(€) ; D_{i, t, s}$ - diameter of pipe $i$ installed in period $t$ for scenario $s(\mathrm{~mm}) ; Y_{t}$ - year when costs will be incurred for period $t$; $C p s_{j, t, s}$ - pumping station costs of pump $j$ in period $t$ for scenario $s(€) ; Q P_{j, d, t, s}$ - discharge of pump $j$ in demand condition $d$ for period $t$ and scenario $s\left(\mathrm{~m}^{3} / \mathrm{s}\right)$ and $H P_{j, d, t, s}$ - head of pump $j$ in demand condition $d$ for period $t$ and for scenario $s(\mathrm{~m})$

The first term of Eq. 4 computes the current value of the cost of the pipes to be installed in the different periods and scenarios, the second term computes the current value of the cost of the pumps for the different periods and for the different scenarios and finally the last term computes the current value of the cost of energy for each period and for each scenario. To compute the current value of the costs of energy, first it is necessary to sum and discount the costs during the $N Y_{t}$ number of years of each the time interval. Them it is required to update these costs by $Y_{t}$ years to year zero of the planning horizon. The pumping station costs are a function of the pump discharge and of the pump head.

So far, the first two terms of the objective function of Eq. 1 have been detailed. The sum of these two costs is intended to represent the full planning horizon cost of the network, considering future uncertainty. The decision variables are the pipe diameters and the head of the pump for each demand condition and for each time interval. The other term of the 
To be cited as: Marques, J., Cunha, M., and D.A. Savić (2015), Using Real Options in the Optimal Design of Water Distribution Networks, Journal of Water Resources Planning and Management (ASCE), Vol. 141, No. 2, 04014052, doi: 10.1061/(ASCE)WR.1943-5452.0000448.

objective function is given in Eq. 5 and computes the regret between the cost of the solution to implement and the optimal cost for each scenario:

$$
R=\sum_{\mathrm{s}=1}^{N S}\left\{\left[\left(\text { Cinitial }^{N} \sum_{\mathrm{t}=2}^{N T I} \text { Cfuture }_{t, s}\right)-\text { Coptimal }_{s}\right]^{2} \cdot \prod_{t=1}^{N T I} \operatorname{prob}_{t, s}\right\} \cdot N f
$$

Where: NS - number of scenarios; Coptimal $_{s}$ - optimal cost design for scenario s (€) and $N f$ normalization factor.

The term given by Eq. 5 aims to find solutions whose costs are as close as possible to all the individual optimal costs, with all the constraints being verified and performing well for all the scenarios. But the scenarios do not have the same probability of occurrence, so the weight of the situations more likely to occur should be higher. Therefore, these differences are multiplied by the probability of occurrence of each path scenario. The regret term is used to introduce the idea of making decisions without perfect information. This means that the design solution to be implemented can be sub-optimal and the regret term is included to represent the risk of such decision. The squared term allows balancing that difference across scenarios. The normalization factor $N f$ is a value used to avoid that the optimization process became high dependent from the regret term. If this term is much higher than the other terms of the objective function, then the progress of the optimization is ruled by the modifications of the regret term. Therefore, it is used a factor playing the role of a normalization to avoid this situation. The value of the normalization factor is problem dependent and was defined according to a kind of sensitivity analysis considering this particular case study.

\subsection{OPTIMAL SOLUTION FOR EACH SCENARIO}

The regret term shown in the objective function of Eq. 5, is based on the minimum cost solution for each scenario. Consequently, the model shown in Eq. 6 is used to find these solutions:

$$
\operatorname{Min} \sum_{\mathrm{t}=1}^{N T I}\left(\begin{array}{l}
\sum_{i=1}^{N P I}\left(\operatorname{Cpipe}_{i}\left(D_{i, t}\right) L_{i}\right) \cdot \frac{1}{(1+I R)^{Y_{t}}}+\sum_{j=1}^{N P U}\left(\operatorname{Cps}_{j, t}\right) \cdot \frac{1}{(1+I R)^{Y_{t}}}+ \\
+\left(\sum_{d=1}^{N D C}\left(C e_{d} \cdot \sum_{j=1}^{N P U} \frac{\gamma \cdot Q P_{j, d, t} \cdot H P_{j, d, t}}{\eta_{j}} \cdot \Delta t_{d}\right) \cdot 365 \cdot \frac{(1+I R)^{N Y_{t}}-1}{I R \cdot(1+I R)^{N Y_{t}}}\right) \cdot \frac{1}{(1+I R)^{Y_{t}}}
\end{array}\right)
$$

The objective function is the sum of 4 periods of the current value of the costs of pipes, pumps and energy. The first term computes the present value of the pipe costs for the year zero. The second term computes the pumping stations' costs. Over the planning horizon the pumps have to be replaced every 20 years, so this cost has to be updated for the first operation 
To be cited as: Marques, J., Cunha, M., and D.A. Savić (2015), Using Real Options in the Optimal Design of Water Distribution Networks, Journal of Water Resources Planning and Management (ASCE), Vol. 141, No. 2, 04014052, doi: 10.1061/(ASCE)WR.1943-5452.0000448.

costs must be updated for each period of the planning horizon and then to the year zero. Adding up these costs for all 4 periods, we get the cost of pipes, pumps and energy for the whole planning horizon of the water distribution network.

The model includes a set of constraints. Eq. (7) is used to verify the nodal continuity equations; Eq. (8) is used to compute the head loss of the pipes; Eq. (9) is used to limit the pressure of the nodes and Eq. (10) is used to guarantee a minimum diameter for the pipes. Furthermore, the optimization model use a candidate diameter for each pipe based on a set of commercial diameters, Eq. (11) and the assignment of only one commercial diameter for each pipe, Eq. (12).

$$
\begin{gathered}
\sum_{i=1}^{N P I} I_{n, i} Q_{i, d, t, s}=Q C_{n, s} \quad \forall n \in N N ; \forall d \in N D C ; \forall t \in N T I ; \forall s \in N S \\
\Delta H_{i, d, t, s}=K_{i} Q_{i, d, t, s}^{\alpha} \quad \forall n \in N N ; \forall d \in N D C ; \forall t \in N T I ; \forall s \in N S \\
P M A X_{n, d, t, s} \geq P_{n, d, t, s} \geq P M I N_{n, d, t, s} \quad \forall n \in N N ; \forall d \in N D C ; \forall t \in N T I ; \forall s \in N S \\
D_{i} \geq D \min _{i} \quad \forall i \in N P I \\
D_{i}=\sum_{d=1}^{N D} Y D_{d, i} . D^{\prime} \operatorname{com}_{d, i} \quad \forall i \in N P I \\
\sum_{d=1}^{N D} Y D_{d, i}=1 \quad \forall i \in N P I
\end{gathered}
$$

Where: $I_{n, i}$-incidence matrix of the network; $Q_{i, d, t, s}-$ flow on the pipe $i$ in demand condition $d$ for period $t$ and scenario $s\left(\mathrm{~m}^{3} / \mathrm{s}\right) ; Q C_{n, d, t, s}$ - consumption in node $n$ in demand condition $d$ for period $t$ and scenario $s\left(\mathrm{~m}^{3} / \mathrm{s}\right) ; N N$ - number of nodes; $\Delta H_{i, s}$ - head loss in pipe $i$ in demand condition $d$ for period $t$ and scenario $s ; K_{i}, \alpha$ - coefficients that depends of the physic characteristics of the pipe $i$; PMAX $X_{n, \text { d.t. }}$ - maximum pressure in node $n$ in demand condition $d$ for period $t$ and scenario $s\left(\mathrm{~m}^{3} / \mathrm{s}\right) ; P_{n, d, t, s}$ - pressure in node $n$ in demand condition $d$ for period $t$ and scenario $s(\mathrm{~m}) ; P M I N_{n, d, t, s}$ - minimum pressure in node $n$ in demand condition $d$ for period $t$ and scenario $s(\mathrm{~m}) ; D_{i}$ - diameter of pipe $i$; $\min _{i}$ - minimum diameter for the pipe $i$; $Y D_{d, i}$ - binary variable to represent the use of the diameter $d$ in pipe $I$; $D$ com ${ }_{d, i}$ - commercial diameter $d$ assigned to pipe $I$ and $N D$ - number of commercial diameters.

Mainly, this study comprises three main elements. The ROs are used to shape the optimization model of Eq. 1. The simulated annealing is used to solve the optimization model and the EPANET (Rossman, 2000) is used to simulate the hydraulics and return the results to verify the constraints of the model. The interaction between the optimizer and the hydraulic simulator is shown in Fig. 3.

Figure 3: Main program diagram 
To be cited as: Marques, J., Cunha, M., and D.A. Savić (2015), Using Real Options in the Optimal Design of Water Distribution Networks, Journal of Water Resources Planning and Management (ASCE), Vol. 141, No. 2, 04014052, doi: 10.1061/(ASCE)WR.1943-5452.0000448.

332

333

334

335

336

337

338

339

340

341

342

343

344

345

346

347

348

349

350

351

352

353

354

355

356

357

358

359

360

361

362

363

364

365

366

367

368

369

370

The program start by input data, then simulated annealing process starts by choosing an initial solution generated randomly in the solution space. To it, is associated a value of the objective function. The current solution is initialized by considering it equal to initial solution. The candidate solution is selected in the neighborhood of the current solution and is given by a random change of current solution. After generation the hydraulic constraints are verified through EPANET and the candidate solution can be accepted or not according to Metropolis criterion (Metropolis, et al. 1953). If it is accepted, this solution will be used as the starting point for the next iteration. If not, the current solution will play this role. After a number of generations, the cooling process is performed and the temperature parameter decreases. The process progresses until a stop criterion is achieved. In the end the results are presented.

The design of the network has to satisfy minimum pressure constraints for 3 different demand conditions and for 4 different subintervals of the planning horizon. The solution thus has to verify 12 different hydraulic conditions for each scenario. Table 4 shows the solutions cost of each scenario.

Table 4: Network cost for the different scenarios

Table 4 presents the cost subdivided into the cost of pipes, cost of PS and energy cost. All of these costs are updated for the year zero. These solutions are used to evaluate the regret term of the objective function of Eq. 1. Each of these solutions takes about 190 seconds to be achieved by the optimization method.

It is possible to draw some conclusions from Table 4. The pipe costs are the greatest percentage of the total costs. Another conclusion is that a decision about the increase of the demand has an impact on the pipe cost in the last period. This can be seen by comparing the construction costs in Table 4 of scenario 1 that considers a demand increase in the last period and scenario 2 were there is no demand increase. It can be seen that if demand does not increase in the last period the cost of the pipes will be lower. This happens because, if there is a substantial increase in the demand, the size of the pipes has to be larger and therefore the cost will be higher.

\section{RESULTS AND DISCUSSIONS}

The model was solved for the case study and the results are presented in Fig. 4.

Figure 4: Solution for Real Options approach 
Decisions have to be made for each node of the decision tree. Fig. 4 presents, for each node, a table with the results of the design, beginning with the diameters in millimetres of the pipes to install in the network. Then the pump heads are presented for each of the three operating conditions considered in the case study and the costs are shown in the last lines, subdivided into the cost of the pipes, the pumps and energy. Finally the last branches of the decision tree present the total cost of the pipes, pumps and energy, updated for the year zero. These figures represent, for each scenario, the total amounts of investment and operating cost that will be expended if that scenario occurs. These future costs of the global solution can be compared with the optimal costs of each scenario. Fig. 4 shows this comparison and enables some conclusions to be achieved. First, the cost of the global solution is higher than the optimal cost of each scenario. In fact considering uncertainty in the process will increase the cost. If the future is well defined, the solution can be designed only for those conditions and not provide the flexibility to accommodate future alterations; the pipes and pumps can be designed to a specific capacity that will reduce the cost of investments.

\section{Figure 5: Cost comparison}

Scenario 1 is the most likely to occur, $\operatorname{prob}_{1}=0.54$, and it can be seen in Fig. 5 that the cost is very similar to the cost of the ROs solution for scenario 1 . This proximity is due to the regret term used in the objective function in Eq. 1. The difference between the cost of the global solution and the optimal cost for each scenario is minimized by the regret term, but this difference is weighed with the probability of each scenario, and the scenarios with high probabilities will further penalize the objective function.

Finally, the expected cost of the solution is computed. The ROs approach considers different scenarios with different probabilities. By adding together all the future weighted costs presented in each node of the decision tree in Fig. 4 it is possible to achieve to the present value of ROs solution, which is $€ 5,442,569$. This is the expected cost for the case study considered for this work and is the sum of the initial solution cost, Cinitial $=€ 4,287,509$ that has to be implemented now plus the weighted costs of all the future options, $\sum_{\mathrm{s}=1}^{N S} \sum_{\mathrm{t}=2}^{N T I}\left(\right.$ Cfuture $_{t, s} \cdot \prod_{n t=2}^{t}$ prob $\left._{n t, s}\right)=€ 1,155,060$. The decision makers can use this cost as the reference for the entire planning horizon operation of the system.

To understand the difference that using ROs will make in the flexible design of water distribution networks, a comparison between the ROs approach and a traditional design is made. The comparison presented covers the first 30 years of operation. The comparisons are presented in Fig. 6.

Figure 6: Comparison between ROs and Traditional design 
To be cited as: Marques, J., Cunha, M., and D.A. Savić (2015), Using Real Options in the Optimal Design of Water Distribution Networks, Journal of Water Resources Planning and Management (ASCE), Vol. 141, No. 2, 04014052, doi: 10.1061/(ASCE)WR.1943-5452.0000448.

410

411

412

413

414

415

416

417

418

419

420

421

422

423

424

425

426

427

428

429

430

431

432

433

434

435

436

437

438

439

440

441

442

443

444

445

446

447

448

449

450

Fig. 5 presents, for each node, a table with the results of the design, beginning with the diameters in millimetres of the pipes to be installed in the network. Then the pump heads are presented for each of the three operating conditions considered in the case study and the costs are shown in the last lines, subdivided into the cost of the pipes, the pumps and energy. These results are presented in two columns: ROs design and a traditional design.

The RO solution given in Fig. 6 is designed for the first period $\mathrm{T}=1$, but consider 2 possible future scenarios: for $\mathrm{T}=2$ a NIA either is installed with a probability of $75 \%$, or it is not installed with a probability of $25 \%$. Another design option for the first period $\mathrm{T}=1$ is a solution planned only to function in the first 20 years of operation. This is the traditional design for this case study and does not take future uncertainty into account. Analyzing the solutions for the first time interval allows us to reach some conclusions. The ROs solution adopts larger pipe diameters than the traditional design, if only the first period is considered. The cost of the ROs solution is $12 \%$ higher than the cost of the traditional design solution. This cost increment is the initial price to pay to have a flexible solution that will perform well for the first 30 years of operation. The pump heads are higher for the traditional design solution due to the smaller diameters of the pipes next to the pumping station. Using larger diameters permits a reduction in head losses and, therefore, less energy is used to pump the water.

As has been shown, the ROs solution has a higher cost for the first period. However, the comparison has to cover the whole 30-year life and it was ascertained that the minimum pressures could not be satisfied in $\mathrm{T}=2$ where the traditional design solution is adopted in the first period. Therefore, this solution has to be reinforced to satisfy the minimum pressure constraints. To compare the solutions, it was considered that the reinforcements can be made by using parallel pipes. The optimization problem assumes that these parallel pipes can be used for all the existing pipe links and considers that the unit pipe cost is the same as that given in Table 1.

To compare the designs the weighted cost of solutions for the 30-year planning horizon is used. The initial cost (Eq. 2) is added to the future weighted cost (Eq. 3) to obtain the value of $€ 4,288,757$ to the ROs design and the value of $€ 4,359,026$ to the design that implies reinforcements of the network. This shows that the cost of the ROs design is $2 \%$ lower than in an inflexible design.

If it is compared to the costs of the traditional design with the ROs design for the 60-year planning horizon and if the decision path of scenario 1 (Fig.2) is considered, a traditional design implies expenditure of more than $270,000 €$ of actualized costs. This solution includes the installation of 11 new parallel pipes. In fact, the ROs solution makes it possible to save on resources if an extended planning horizon analysis is performed. 
To be cited as: Marques, J., Cunha, M., and D.A. Savić (2015), Using Real Options in the Optimal Design of Water Distribution Networks, Journal of Water Resources Planning and Management (ASCE), Vol. 141, No. 2, 04014052, doi: 10.1061/(ASCE)WR.1943-5452.0000448.

451

452

453

454

455

456

457

458

459

460

461

462

463

464

465

466

467

468

469

470

471

472

473

474

475

476

477

478

479

480

481

482

483

484

485

486

487

488

489

From these comparisons it is also possible to conclude that the length of the planning horizon is very important for the initial design. However, the longer the planning horizon the more uncertainties arise and the design should be adjusted between different possible future scenarios. The ROs approach makes an important contribution because it can handle future uncertainty. But design flexibility has a cost. In this comparison, the ROs solution is $12 \%$ more costly than the traditional solution designed only for the first period. However, if a 30year operation planning horizon is considered the ROs solution costs less than a solution that ignores different future possible scenarios. This is a proactive way to arrive at a minimum cost design solution for an extended planning horizon.

\section{CONCLUSIONS}

This work describes an innovative ROs approach used for a decision making process under uncertainty, in the field of water supply networks' design. The optimization model presented in this paper tries to minimize costs over the whole planning horizon. Based on trying to delay some decisions for the future, ROs enables total investment to be reduced. But this delay comes at a cost. The initial solution has to be flexible enough to accommodate all the future conditions, and some pipes have to be overdesigned.

The design of a specific case study was used to explain the approach. Different options were considered for the infrastructure and the planning horizon was subdivided into periods with the aim of making midcourse corrections or additional investments. The results were presented by a decision tree, with the value for the different decision variables as well as the total amounts of investment and operating cost that will be expended. The future costs of the ROs solutions were compared with the optimal costs of each scenario.

A comparison between the ROs approach and a traditional design was made. Results show that the ROs solution makes it possible to save on resources if an extended and uncertain planning horizon analysis is performed.

The ROs philosophy tries to find opportunities to incorporate flexibility into decision making so as to mitigate the potential impact of future uncertainties, which in turn creates opportunities for adaptation. For the case study, an adaptable network design for a 60 -year planning horizon had an extra initial cost, since a flexible solution is more costly than a solution that does not take the future into account. However, the latter solutions will not have sufficient robustness to accommodate the future scenarios, and therefore some pipes in the network will need to be reinforced, for example by installing new parallel pipes. These reinforcements will of course increase the overall cost of the system over its entire planning 
To be cited as: Marques, J., Cunha, M., and D.A. Savić (2015), Using Real Options in the Optimal Design of Water Distribution Networks, Journal of Water Resources Planning and Management (ASCE), Vol. 141, No. 2, 04014052, doi: 10.1061/(ASCE)WR.1943-5452.0000448.

horizon. The real value of ROs is their ability to adapt the solution to different future possible decisions.

\section{ACKNOWLEDGMENTS}

This work has been financed by FEDER funds through the Programa Operacional Factores de Competitividade - COMPETE, and by national funds from FCT -Fundação para a Ciência e Tecnologia under grant PTDC/ECM/64821/2006. The participation of the first author in the study is supported by FCT - Fundação para a Ciência e Tecnologia through Grant SFRH/BD/47602/2008.

\section{REFERENCES}

Aarts, E., and Korst, J. (1989). "Simulated annealing and Boltzmann machines: a stochastic approach to combinatorial optimization and neural computing". (I. John Wiley \& Sons, Ed.). New York, NY, USA.

Afonso, P. M., \& Cunha, M. C. (2007). "Robust Optimal Design of Activated Sludge Bioreactors". Journal of Environmental Engineering, 133(1), 44-52.

Black, F., and Scholes, M. (1973). "The Pricing of Options and Corporate Liabilities". Journal of Political Economy, The University of Chicago Press, 81(3), 637-654.

Buurman, J., Zhang, S., \& Babovic, V. (2009). "Reducing Risk Through Real Options in Systems Design: The Case of Architecting a Maritime Domain Protection System". Risk Analysis, 29(3), 366-379.

Costa, A., Cunha, M., Coelho, P., \& Einstein, H. (2013)." Solving High-Speed Rail Planning with the Simulated Annealing Algorithm". Journal of Transportation Engineering, 139(6), 635-642.

Cunha, M. C. (1999). "On Solving Aquifer Management Problems with Simulated Annealing Algorithms". Water Resources Management, 13(3), 153-170.

Cunha, M. C., and Sousa, J. (1999). "Water Distribution Network Design Optimization: Simulated Annealing Approach". Journal of Water Resources Planning and Management, ASCE, 125(4), 215-221.

DWSD (2004). "Comprehensive Water Master Plan". Final Report, Task C: Rehabilitation and Replacement Program, Detroit Water and Sewerage Department, Contract No. CS1278, pag. 133.

Haimes, Y. Y. (1998). "Sustainable Operation of Threatened Infrastructures". Journal of Infrastructure Systems, ASCE, 4(1), 1-4.

He, H., and Pindyck, R. S. (1992). "Investments in Flexible Production Capacity". Journal of Economic Dynamics and Control, 16(3-4), 575-599.

Huang, D., Vairavamoorthy, K., and Tsegaye, S. (2010). "Flexible Design of Urban Water Distribution Networks". World Environmental and Water Resources Congress, 42254236.

Merton, R. C. (1973). "Theory of Rational Option Pricing”. The Bell Journal of Economics and Management Science, The RAND Corporation, 4(1), 141-183. 
To be cited as: Marques, J., Cunha, M., and D.A. Savić (2015), Using Real Options in the Optimal Design of Water Distribution Networks, Journal of Water Resources Planning and Management (ASCE), Vol. 141, No. 2, 04014052, doi: 10.1061/(ASCE)WR.1943-5452.0000448.

Metropolis, N., Rosenbluth, A. W., Rosenbluth, M. N., Teller, A. H., \& Teller, E. (1953). "Equation of State Calculations by Fast Computing Machines". The Journal of Chemical Physics, 21(6).

Myers, S. C. (1977). "Determinants of corporate borrowing". Journal of Financial Economics, 5(2), 147-175.

Nembhard, H. B. e Aktan, M., (2010). "Real options in engineering design, operations, and management". CRC Press, 253p.

Neufville, R., Scholtes, S., and Wang, T. (2006). "Real Options by Spreadsheet: Parking Garage Case Example”. Journal of Infrastructure Systems, ASCE, 12(2), 107-111.

Paddock, J. L., Siegel, D. R., and Smith, J. L. (1988). "Option Valuation of Claims on Real Assets: The Case of Offshore Petroleum Leases". Quarterly Journal of Economics, JSTOR, 103(3), 479-508.

Roberts, K., and Weitzman, M. L. (1981). "Funding criteria for research, development, and exploration projects". Econometrica, JSTOR, 49(5), 1261-1288.

Rossman, L.A. (2000). "Epanet2 Users Manual". U.S. Environmental Protection Agency, Cincinnati, $\mathrm{OH}$.

Suttinon, P., and Nasu, S. (2010). "Real Options for Increasing Value in Industrial Water Infrastructure". Water Resources Management, Springer Netherlands, 24(12), 28812892.

Taher, S. A., and Labadie, J. W. (1996). "Optimal Design of Water-Distribution Networks with GIS". Journal of Water Resources Planning and Management, ASCE, 122(4), 301311.

Tannous, G. F. (1996). “Capital Budgeting for Volume Flexible Equipment". Decision Sciences, Blackwell Publishing Ltd, 27(2), 157-184.

Wang, T., and Neufville, R. D. (2004). "Building Real Options into Physical Systems with Stochastic Mixed-Integer Programming". 8th Annual Real Options International Conference, 23-32.

Woodward, M., Gouldby, B., Kapelan, Z., Khu, S.-T., and Townend, I. (2011). "Real Options in flood risk management decision making". Journal of Flood Risk Management, 4(4), 339-349.

Wu, W., Simpson, A. R., and Maier, H. R. (2010). "Accounting for Greenhouse Gas Emissions in Multiobjective Genetic Algorithm Optimization of Water Distribution Systems". Journal of Water Resources Planning and Management, ASCE, 136(5), 146155.

Zeferino, J. A., Cunha, M. C., \& Antunes, A. P. (2012). "Robust optimization approach to regional wastewater system planning". Journal of Environmental Management, 109(0), $113-122$.

Zhang, S. X., \& Babovic, V. (2011). An evolutionary real options framework for the design and management of projects and systems with complex real options and exercising conditions. Decision Support Systems, 51(1), 119-129.

Zhang, S. X., and Babovic, V. (2012). "A real options approach to the design and architecture of water supply systems using innovative water technologies under uncertainty". Journal of Hydroinformatics, 14(1), 13-29.

Table 1: Diameter, unit costs, Hazen-Williams coefficients

\begin{tabular}{c|c|c}
\hline $\begin{array}{c}\text { Diameters } \\
(\mathrm{mm})\end{array}$ & $\begin{array}{c}\text { Unit costs } \\
(€ / \mathrm{m})\end{array}$ & $\begin{array}{c}\text { Hazen-Williams } \\
\text { Coefficients }\end{array}$ \\
\hline
\end{tabular}


To be cited as: Marques, J., Cunha, M., and D.A. Savić (2015), Using Real Options in the Optimal Design of Water Distribution Networks, Journal of Water Resources Planning and Management (ASCE), Vol. 141, No. 2, 04014052, doi: 10.1061/(ASCE)WR.1943-5452.0000448.

579

580

581

582

583

584

585

586

587

\begin{tabular}{l|rrrrrrrr}
\hline & \multicolumn{7}{|c}{ Scenarios } \\
\cline { 2 - 9 } & \multicolumn{1}{|c}{1} & \multicolumn{1}{|c}{3} & \multicolumn{1}{c}{4} & \multicolumn{1}{c}{5} & \multicolumn{1}{c}{6} & \multicolumn{1}{c}{7} & 8 \\
\hline \hline Construction cost $(€)$ & $3,992,269$ & $3,682,766$ & $3,794,636$ & $3,512,817$ & $3,242,176$ & $3,215,033$ & $2,937,053$ & $2,975,677$ \\
\hline Cost of energy $(€)$ & $1,190,024$ & $1,156,966$ & $1,163,855$ & $1,137,703$ & 756,193 & 717,879 & 779,515 & 733,601 \\
\hline Cost of the pumps $(€)$ & 389,067 & 382,747 & 387,690 & 383,855 & 318,121 & 312,560 & 322,491 & 315,145 \\
\hline Total costs $(€)$ & $5,571,360$ & $5,222,478$ & $5,346,181$ & $5,034,376$ & $4,316,491$ & $4,245,471$ & $4,039,059$ & $4,024,423$ \\
\hline
\end{tabular}

Table 2: Characteristics of the new nodes

\begin{tabular}{c|c|c|c|c|c|c|c}
\hline \multirow{2}{*}{ Node } & \multirow{2}{*}{$\begin{array}{c}\text { Ground } \\
\text { elevation (m) }\end{array}$} & \multicolumn{3}{|c|}{ Nodal consumption (1/s) } & \multicolumn{3}{c}{ Minimum pressure (m) } \\
\cline { 3 - 7 } & & $(1)$ & $(2)$ & $(3)$ & $(1)$ & $(2)$ & $(3)$ \\
\hline \hline 11 & 298.56 & 18.927 & 13.249 & 18.927 & 35.0 & 35.0 & 14.0 \\
12 & 289.56 & 31.545 & 22.082 & 31.545 & 35.0 & 35.0 & 14.0 \\
13 & 243.84 & 18.927 & 13.249 & 18.927 & 35.0 & 35.0 & 14.0 \\
14 & 243.84 & 12.618 & 8.833 & 12.618 & 35.0 & 35.0 & 14.0 \\
\hline
\end{tabular}

Table 3: Characteristics of the new pipes

\begin{tabular}{c|c|c|c}
\hline Pipe & Initial Node & Final Node & Length $(\mathrm{m})$ \\
\hline \hline 12 & 6 & 11 & 1609.344 \\
13 & 7 & 12 & 1609.344 \\
14 & 11 & 12 & 1609.344 \\
15 & 3 & 13 & 1609.344 \\
16 & 4 & 14 & 1609.344 \\
17 & 13 & 14 & 1609.344 \\
\hline
\end{tabular}

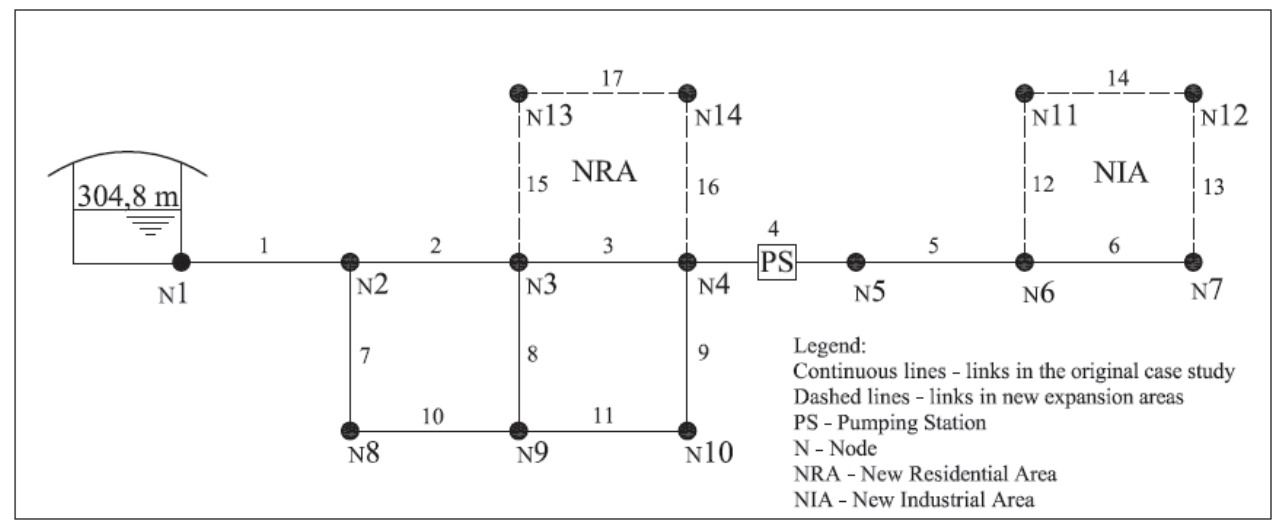


To be cited as: Marques, J., Cunha, M., and D.A. Savić (2015), Using Real Options in the Optimal Design of Water Distribution Networks, Journal of Water Resources Planning and Management (ASCE), Vol. 141, No. 2, 04014052, doi: 10.1061/(ASCE)WR.1943-5452.0000448.

595

596

597

598

599

600

601

602

603

604

605

606

607

608

609

610

611

612

613

614

615

616

617
Figure 1: Water distribution network inspired from Taher \& Labadie (1996) with possible expansion areas

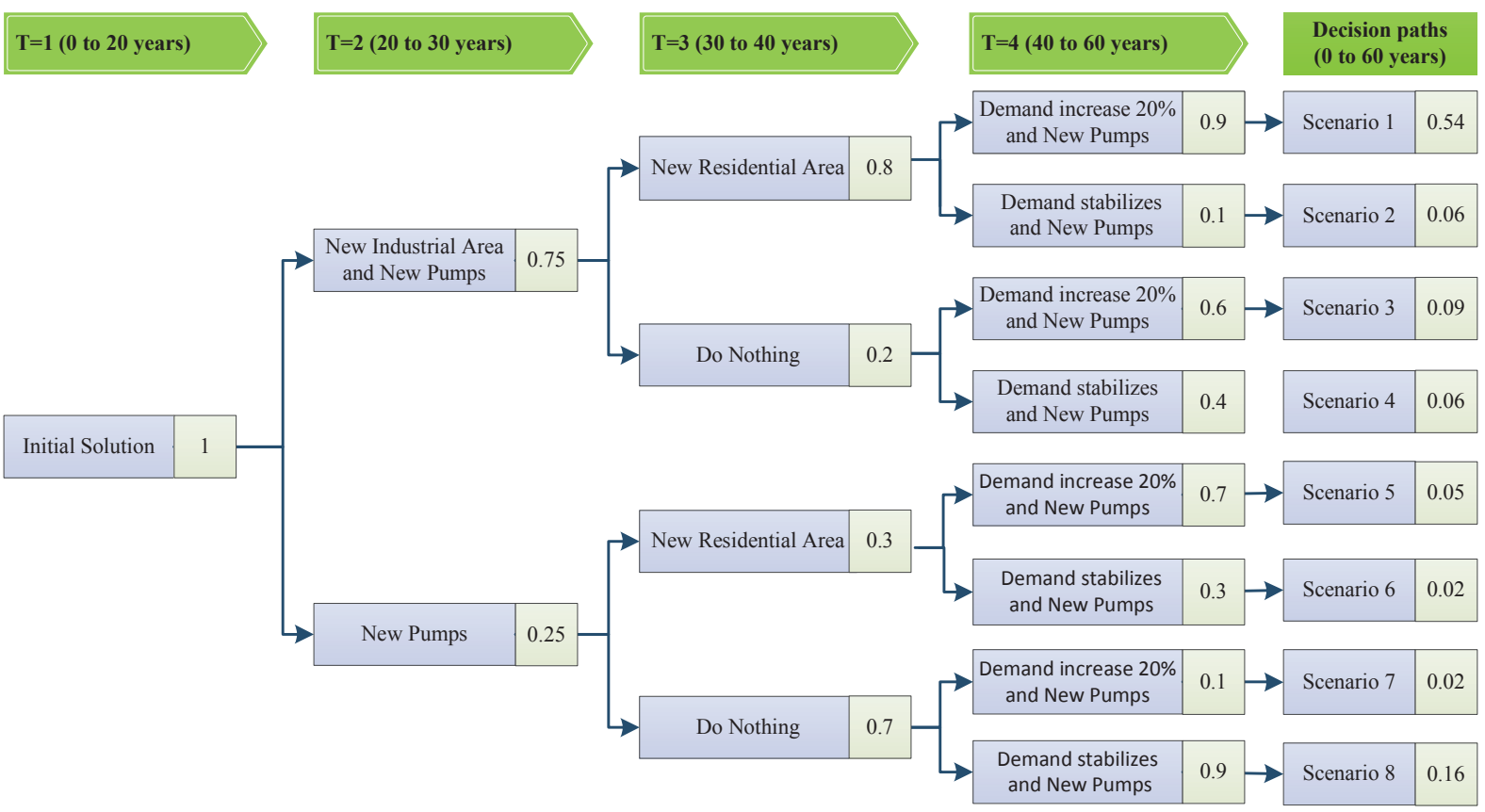

Figure 2: Decision tree for the planning horizon 
To be cited as: Marques, J., Cunha, M., and D.A. Savić (2015), Using Real Options in the Optimal Design of Water Distribution Networks, Journal of Water Resources Planning and Management (ASCE), Vol. 141, No. 2, 04014052, doi: 10.1061/(ASCE)WR.1943-5452.0000448.

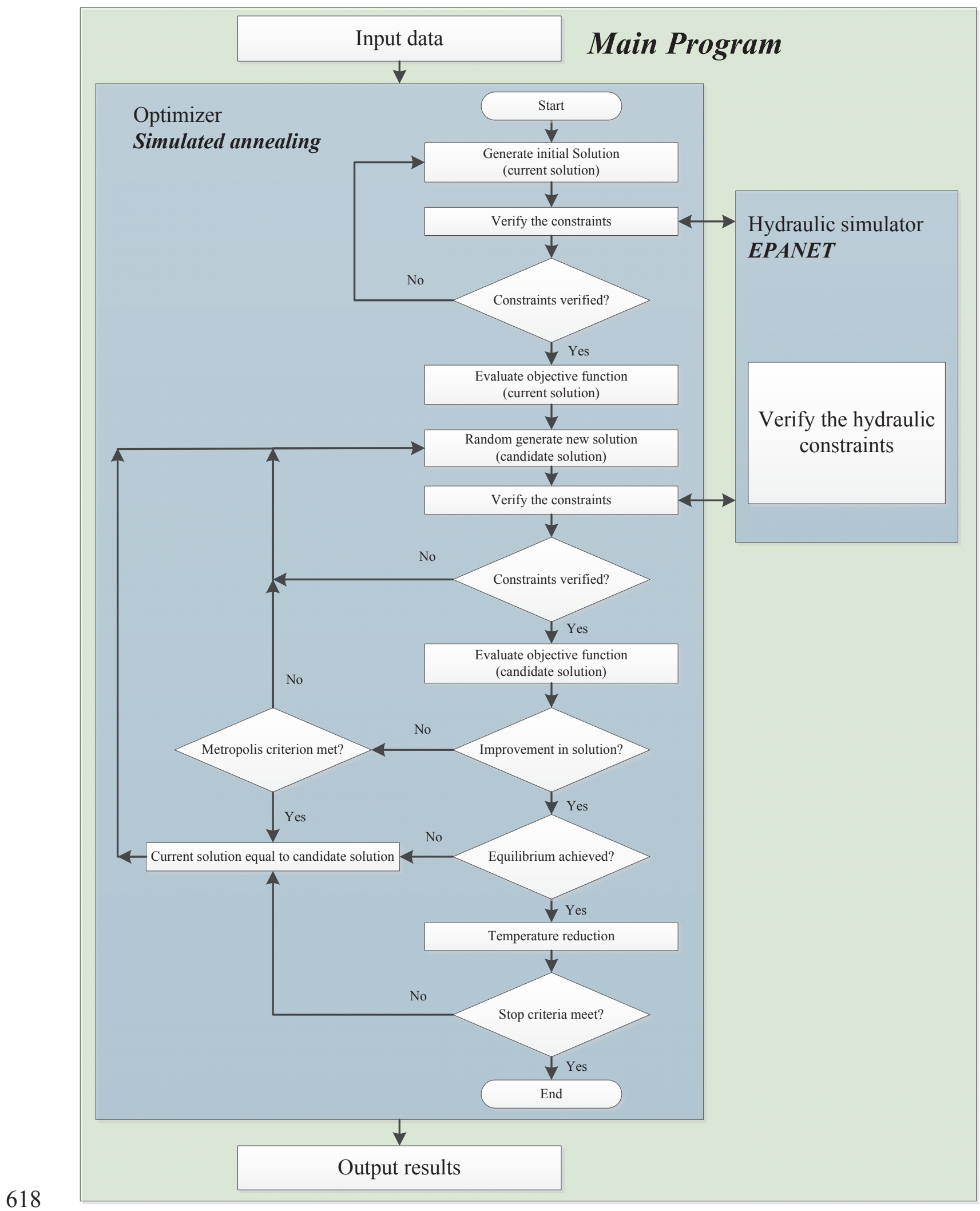


To be cited as: Marques, J., Cunha, M., and D.A. Savić (2015), Using Real Options in the Optimal Design of Water Distribution Networks, Journal of Water Resources Planning and Management (ASCE), Vol. 141, No. 2, 04014052, doi: 10.1061/(ASCE)WR.1943-5452.0000448.

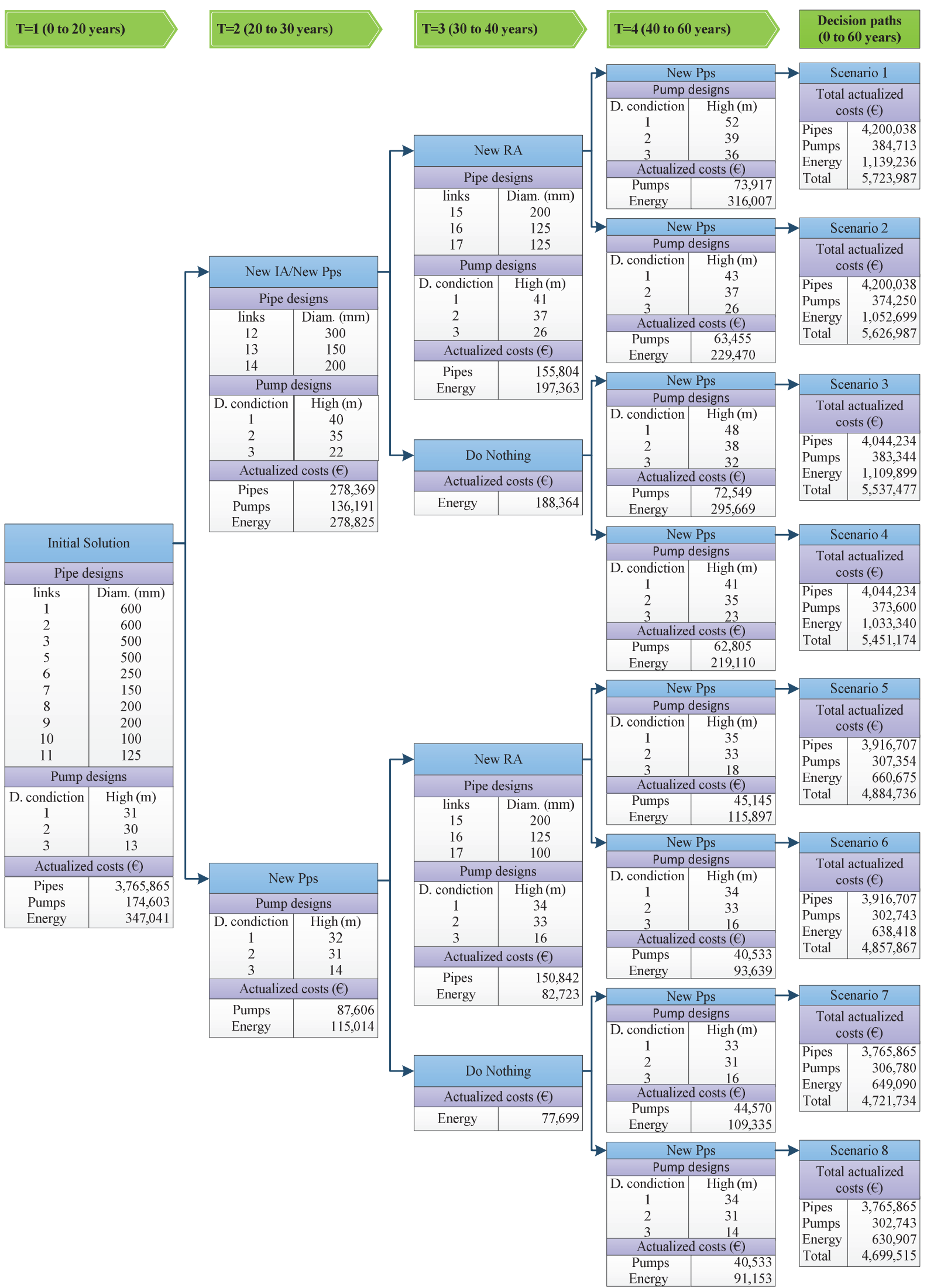

Figure 4: Solution for Real Options approach 
To be cited as: Marques, J., Cunha, M., and D.A. Savić (2015), Using Real Options in the Optimal Design of Water Distribution Networks, Journal of Water Resources Planning and Management (ASCE), Vol. 141, No. 2, 04014052, doi: 10.1061/(ASCE)WR.1943-5452.0000448.

625

626

627

628

629

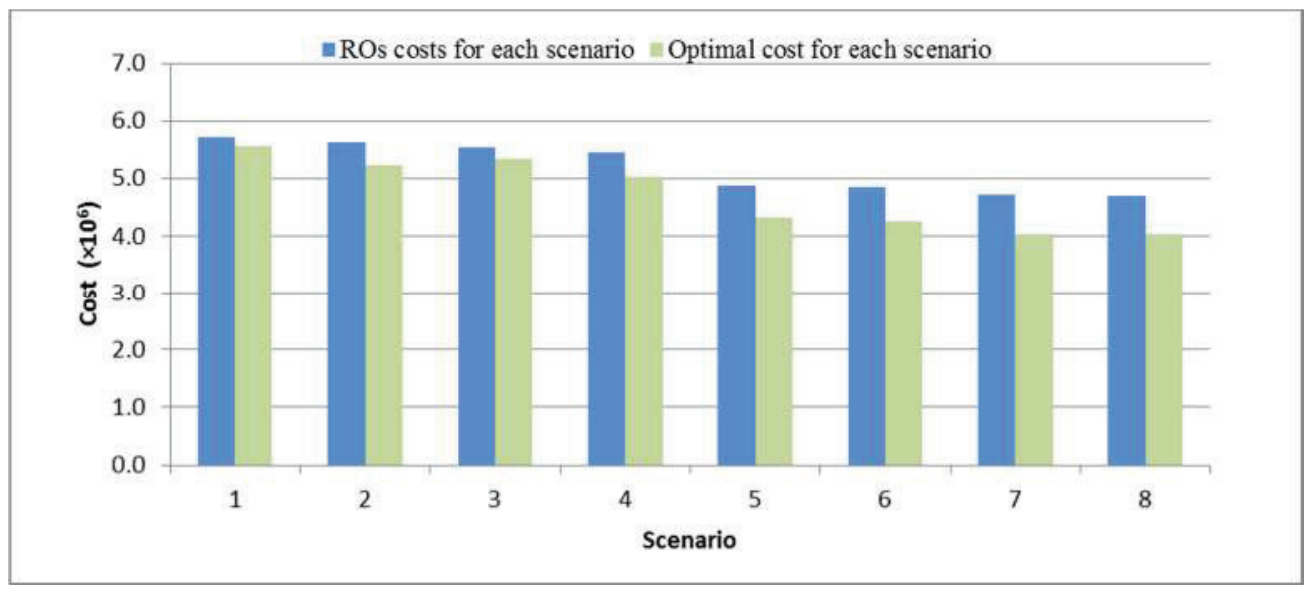

Figure 5: Cost comparison

\begin{tabular}{|c|c|c|c|c|c|}
\hline \multicolumn{3}{|c|}{$T=1(0$ to 20 years $)$} & \multicolumn{3}{|c|}{$T=2(20$ to 30 years $)$} \\
\hline & & & \multicolumn{3}{|c|}{ New IANew Pps } \\
\hline & & & Pipe designs & $\mathrm{RO}$ & Traditional \\
\hline & & & $\begin{array}{c}\text { links } \\
12 \\
13 \\
14\end{array}$ & $\begin{array}{c}\text { Diam. (mm) } \\
200 \\
200 \\
100\end{array}$ & $\begin{array}{c}\text { Diam. (mm) } \\
300 \\
100 \\
200\end{array}$ \\
\hline & & & Pipe designs & $\mathrm{RO}$ & Traditional \\
\hline \multicolumn{3}{|c|}{ Initial Solutions } & \multirow{3}{*}{$\begin{array}{c}\text { links } \\
1 \\
2 \\
8 \\
\end{array}$} & & \multirow{3}{*}{$\begin{array}{c}\text { Diam. (mm) } \\
300 \\
350 \\
125\end{array}$} \\
\hline Pipe designs & $\mathrm{RO}$ & traditional & & & \\
\hline links & \multirow{3}{*}{$\begin{array}{c}\text { Diam. }(\mathrm{mm}) \\
500 \\
400\end{array}$} & \multirow{2}{*}{$\begin{array}{c}\text { Diam. (mm) } \\
400\end{array}$} & & & \\
\hline 1 & & & Pump designs & RO & Traditional \\
\hline 2 & & 350 & D. condiction & High (m) & High (m) \\
\hline 3 & 400 & 350 & 1 & 60 & 78 \\
\hline 5 & 400 & 300 & 2 & 45 & 53 \\
\hline 6 & 350 & 200 & 3 & 53 & 76 \\
\hline 7 & 150 & 150 & Costs $(€)$ & $\mathrm{RO}$ & Traditional \\
\hline 8 & 150 & 100 & Pipes & 240,146 & 706,575 \\
\hline 9 & 250 & 250 & Pumps & 150,579 & 161,037 \\
\hline 10 & 100 & 125 & Energy & 396,504 & 497,731 \\
\hline & 100 & 100 & Total & 787,229 & $1,365,343$ \\
\hline Pump designs & $\mathrm{RO}$ & Traditional & & & \\
\hline \multirow{3}{*}{$\begin{array}{l}\text { D. condiction } \\
1 \\
2 \\
3\end{array}$} & \multirow{3}{*}{$\begin{array}{c}\text { High }(\mathrm{m}) \\
36 \\
32 \\
24\end{array}$} & \multirow{3}{*}{$\begin{array}{c}\text { High }(\mathrm{m}) \\
46 \\
37 \\
47\end{array}$} & \multicolumn{3}{|c|}{ New Pps } \\
\hline & & & Parallel pipes & $\mathrm{RO}$ & Traditional \\
\hline & & & links & & Diam (mm) \\
\hline Costs $(€)$ & $\mathrm{RO}$ & Traditional & $\begin{array}{r}8 \\
\text { Pumnde }\end{array}$ & & 200 \\
\hline Pipes & $3,075,456$ & $2,576,560$ & Pump designs & RU & Traditional \\
\hline Pumps & 179,708 & 190,531 & D. condiction & $\underset{40}{\operatorname{High}(m)}$ & $\underset{59}{\operatorname{High}(\mathrm{m})}$ \\
\hline Energy & 385,198 & 473,242 & $\begin{array}{l}1 \\
2\end{array}$ & $\begin{array}{l}40 \\
35\end{array}$ & 41 \\
\hline Total & $3,640,362$ & $3,240,333$ & 3 & 28 & 61 \\
\hline & & & Costs $(€)$ & $\mathrm{RO}$ & Traditional \\
\hline & & & Pipes & 0 & 88,138 \\
\hline & & & Pumps & 92,464 & 101,752 \\
\hline & & & Energy & 139,428 & 188,854 \\
\hline & & & Total & 231,892 & 378,744 \\
\hline
\end{tabular}


To be cited as: Marques, J., Cunha, M., and D.A. Savić (2015), Using Real Options in the Optimal Design of Water Distribution Networks, Journal of Water Resources Planning and Management (ASCE), Vol. 141, No. 2, 04014052, doi: 10.1061/(ASCE)WR.1943-5452.0000448.

Figure 6: Comparison between ROs and traditional design 